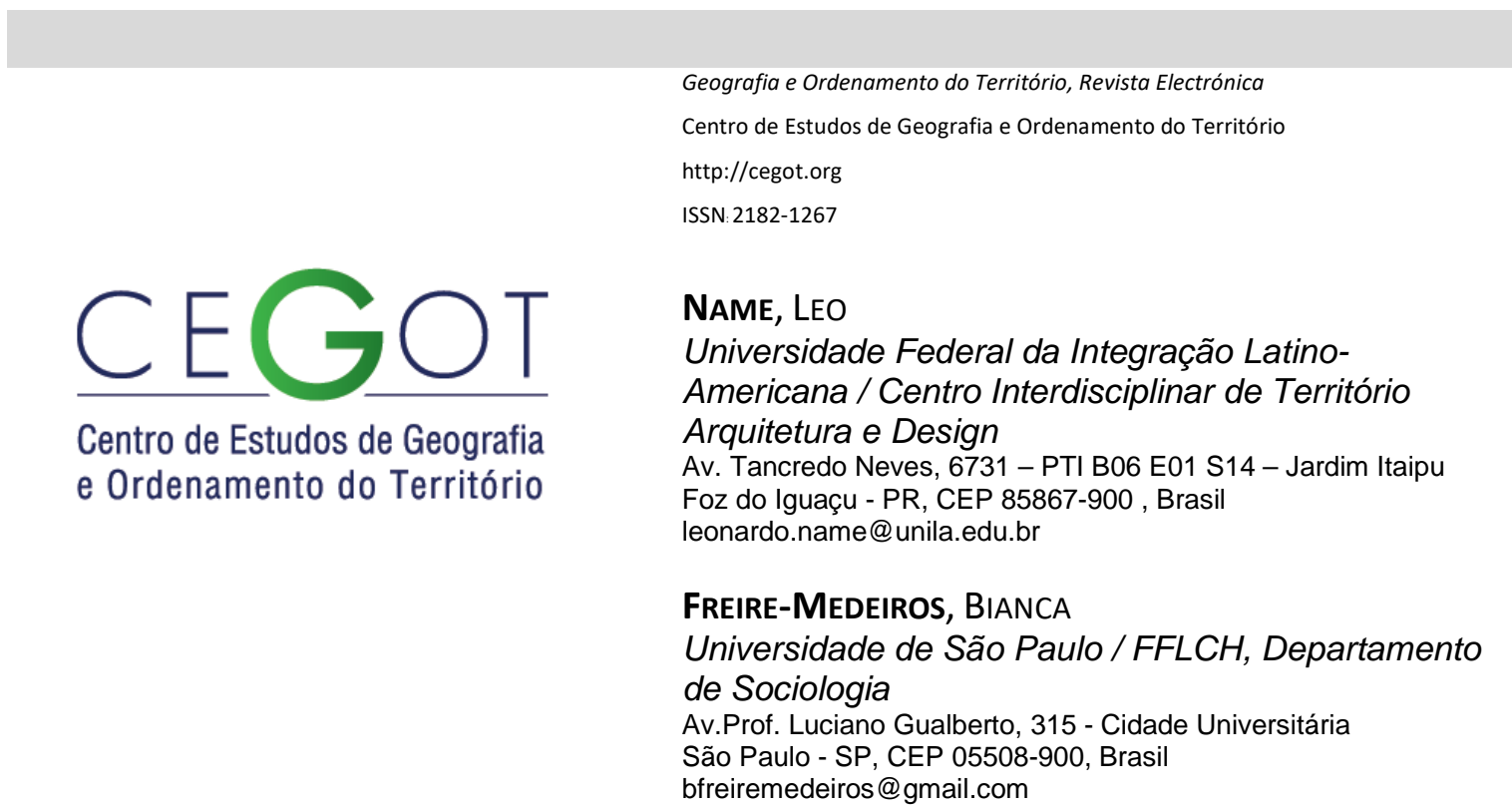

\title{
Teleféricos na paisagem da "favela" latino-americana: mobilidades e colonialidades ${ }^{1}$
}

\author{
Cable cars in the landscape of the Latin-American "favela": mobilities and \\ colonialities
}

Referência: Name, Leo; Freire-Medeiros, Bianca (2017). Teleféricos na paisagem da "favela" latino-americana: mobilidades e colonialidades. Revista de Geografia e Ordenamento do Território (GOT), n.o 11 (junho). Centro de Estudos de Geografia e Ordenamento do Território, p. 263-282, dx.doi.org/10.17127/got/2017.11.012

\section{RESUMO}

Com base em um diálogo entre as reflexões produzidas no Paradigma das Novas Mobilidades e nos Estudos Decoloniais, examinamos os teleféricos que, na última década, passaram a compor a paisagem de áreas pobres e segregadas da América Latina. Partimos da premissa de que, no contexto do planejamento urbano estratégico, esse novo dispositivo de mobilidade é uma intervenção expressiva que gera competitividade devido aos novos marcos visuais que insere na paisagem e às novas imagens da pobreza que instituem. Muito mais que opções técnicas neutras para o transporte urbano, os teleféricos inauguram um regime visual que projeta uma ideia de modernidade e promete a mudança social, mas que na verdade convertem a pobreza, como diferença colonial, em valor estético e simbólico.

\footnotetext{
${ }^{1} \mathrm{Na}$ América Latina, são muitos os termos que nominam os assentamentos informais de baixa renda: "favela" (Brasil), "barriada" (México e Porto Rico), "barrio" (Colômbia, Equador, Honduras, Panamá e Venezuela), "campamento" (Chile), “cantegril” (Uruguai), "Ilegaypón” (Cuba), "pueblo joven" (Peru), "tugurio" (Costa Rica e El Salvador) e "villa miseria" (Argentina), por exemplo. Além disso, no Brasil "teleférico" é a palavra utilizada para referir-se ao dispositivo de mobilidade por cabos, mas nos demais países hispanohablantes são comuns "metrocable", "andarivel" e "aerosilla". Optamos por sempre utilizar os termos no português do Brasil.
} 
Palavras-chave: teleféricos; paisagem; imagem; favela; América Latina; Paradigma das Novas Mobilidades; Estudos Decolonais.

\section{ABSTRACT}

Based on a dialogue between the reflections produced in the New Mobilities Paradigm and the Decolonial Studies, we examine the cable cars that since the last decade are spectacular part of landscape of the poor and segregated areas of Latin America. Our premise is that in the context of strategic urban planning this new mobility is an expressive intervention that generates competitiveness due to the new visual landmarks that it inserts in the landscape and the new images that institute. Far more than neutral technical options for urban transportation, these cable cars inaugurate a visual regime that designs an idea of modernity and promises social change, but which in fact converts poverty, as a colonial difference, into aesthetic and symbolic value.

Key-words: cable cars; landscape; image; favela; Latin America; New Mobilities Paradigm; Decolonial Studies.

\section{Introdução}

Na América Latina, por muito tempo os teleféricos estiveram associados à prática de esportes de inverno, como no caso de Bariloche (Argentina), ou à contemplação em paisagens montanhosas, como no Rio de Janeiro (Brasil) ou em Mérida (Venezuela). Esse quadro de referência alterou-se radicalmente quando, em 2004, o Instituto Municipal de Medellín, na Colômbia, inaugurou um sistema de transporte por cabos com o objetivo de integrar o tecido formal da cidade aos assentamentos precários de baixa renda (Fukuyama e Colby, 2011).

"O mais belo para os mais humildes" - foi o que disse o então prefeito da cidade, Sergio Fajardo, com vistas a esclarecer os princípios do chamado "Urbanismo Social". Ao que seu sucessor, Alonso Salazar, acrescentou a tarefa de "ativar a força da estética como motor de mudança social" (Brand e Dávila, 2012). Esses dois lemas traduziram-se empiricamente por meio de obras infraestruturais e construções arquitetônicas de forte impacto estético conjuntos habitacionais, parques-biblioteca e teleféricos. Desde então esse dispositivo de mobilidade foi exportado para outras áreas íngremes com ocupações irregulares, marcadas por violência e onde habita uma população pobre e geralmente não branca, em cidades como Bogotá, Soacha e Cali, na própria Colômbia; El Alto e La Paz, na Bolívia; Caracas, na 
Venezuela; e, no Brasil, no Rio de Janeiro (Ortiz e Urdaneta, 2012; Dávila e Daste, 2011; Dávila, Ed., 2012; Dávila e Brand, 2012; Brand e Dávila, 2012; Freire-Medeiros e Name, 2015 e 2017).

Um enfoque mais tradicional tende a priorizar, no exame da emergência desses novos dispositivos e de sua popularização no contexto das políticas urbanas de transporte e acessibilidade, os aspectos ditos técnicos. Algumas análises dão destaque analítico à (in)capacidade dos sistemas de transporte por cabos em lidar com o aumento da dispersão, da descontinuidade e da expansão intraurbanas - acentuadamente presentes nas maiores cidades latino-americanas (Borsdorf, 2003; Frediani, 2009; Limonad, 2007; Reis, 2006). Outras analisam a relação entre investimentos públicos e retornos financeiros, a eficiência do sistema, sua condição de meio de transporte de massa limpo (sem emissões diretas de dióxido de carbono) e as vantagens comparativas com meios de transporte de massa mais usuais, como ônibus, barcas e trens (Keeling, 2007 e 2009). No entanto, ainda que alguns escritos insiram a discussão sobre mobilidade urbana no contexto mais amplo da qualidade de vida, justiça espacial e direito à cidade (Leibler e Musset, 2010; Paquette, 2014; Rolnik e Klintowitz, 2011; Ureta, 2008), outros assumem os riscos oriundos dos traços positivistas da geografia dos transportes (Cresswell, 2010, p. 554).

Nossa intenção, porém, não é avaliar a distribuição espacial das opções de transporte ou sua eficiência, posto que entendemos a mobilidade urbana como parte de sistemas complexos que correlacionam questões materiais e simbólicas. Cremos que o sucesso do Urbanismo Social medellinense, e em especial de seus teleféricos, entre administrações de outras cidades da América Latina se explica na inserção da favela, como paisagem e imagem, na lógica "estetizante" e "mercadófila" (Cf. de Souza, 2001) do planejamento urbano estratégico - isto é, na crescente execução de projetos urbanos, especialmente a partir da década de 1990, anunciados como capazes de promover crescimento econômico, competitividade e envolvimento de empresas e empresários na administração pública (Ascher, 2001; Borja e Castells, 1998; de Souza, 2001; Harvey, 1989; Novais, 2010; Vainer, 2000). O amplo leque de intervenções no subcontinente latino-americano inclui remodelações urbanas em torno de megaeventos internacionais, revitalizações de parques e áreas portuárias, inserção de novos equipamentos culturais projetados por nomes 
célebres da arquitetura internacional e instalações de infraestruturas, inclusive as de mobilidade e acessibilidade. O objetivo destas intervenções é atribuir elementos competitivos não somente tributários das funcionalidades e serviços que apresentam, mas também dos novos marcos visuais na paisagem que instituem. Afinal, se os teleféricos de Medellín, logo instalados em outras favelas da América Latina, são dispositivos de mobilidade, a eles também se associa conjunto imagético contundente: perspectivas digitais quando ainda nas fases de projeto, imagens de obras em execução ou fotografias da imprensa, moradores e turistas, por exemplo.

Temos como referência o chamado "paradigma das novas mobilidades" (PNM), que advoga centralidade analítica a tudo que se move: pessoas em seus deslocamentos diários, viagens de trabalho ou de férias; as várias modalidades de transporte nas cidades e entre as cidades; produtos que acionam sistemas logísticos; fluxos de bytes e informações e, o que aqui mais nos interessam, imagens (Elliot e Urry 2010; Sheller e Urry, 2006; Urry, 2007). A abordagem do PNM aponta a existência crescente de "viagens virtuais" e, mais especificamente, "viagens imaginativas"2 (Urry, 2000, 2002 e 2007; Szerszynski e Urry, 2002 e 2006; Larsen e Urry, 2011a e 2011b), isto é, um acesso constante a lugares por meio de imagens em circulação global (Gitlin, 2001; Name, 2013). As reflexões com base no PNM nos ajudam, então, a entender os novos teleféricos como intervenções expressivas e sensoriais que atraem o olhar para as paisagens das favelas e as enquadram em novas molduras semânticas. E se estes dispositivos de mobilidade não são o único exemplo de transformações urbanas com vistas à produção de imagens, são particularmente interessantes porque muito mais que opções técnicas, representam a emergência de novos pontos de vista que, por sua vez, geram novas imagens da pobreza - notadamente de sua paisagem -, que se agregam ao trânsito global de imagens que as favelas já possuem (Freire-Medeiros, 2009).

\footnotetext{
${ }^{2}$ A expressão original em inglês é imaginative travels. A despeito da polissemia do adjetivo "imaginativas", em português, "viagens imaginativas" é uma tradução mais apropriada que "viagens imaginárias". A última poderia, por um lado, levar à leitura sobre algo fantasioso, irreal ou ficcional nestas viagens, quando a literatura do PNM refere-se a certo deslocamento virtual obtido pela profusão e circulação de imagens; por outro, sobre um alinhamento teórico do mobilities turn à larga e diversificada literatura dos estudos do imaginário (Castoriadis, Jung, Eliade, Bachelard e Gruzinski, por exemplo), o que não é o caso.
} 
Não ignoramos, contudo, as críticas ao PNM, que o acusam de reproduzir o eurocentrismo ao naturalizar preconcepções de modernidade e cosmopolitismo, sobrevalorizando a hipermobilidade como algo sempre positivo e a ser atingido universalmente (Cohen e Cohen, 2015a e 2015b; Cohen e Gössling, 2015; Freire-Medeiros e Name, 2017). O eurocentrismo permite, ainda, que muitos autores e autoras se mostrem insensíveis tanto às iniquidades intrínsecas ao contexto global contemporâneo, que incentiva que uns se movam e outros não, como ao legado do colonialismo, instituidor do conjunto de assimetrias de poder presentes na América Latina e atuante sobre essas mobilidades e imobilidades - de pessoas, objetos, imagens e, claro, de conhecimento (Freire-Medeiros, 2013; Freire-Medeiros e Name, 2013, 2015 e 2017; Name, 2013). Afinal, a produção e circulação do saber, particularmente em ciências sociais, não escapam à colonização epistêmica do Sul Global pelo Norte, sendo atravessadas por aquilo que Quijano (1992; 2000a e 2000b), Mignolo (2000, 2011) e Grosfoguel (2006) indicam ser "colonialidades": as dimensões de poder constitutivas do colonialismo e de seus legados, ainda presentes.

Buscamos, portanto, posicionar as "mobilidades" sob o prisma das "colonialidades". Por isso, na próxima seção, promoveremos o diálogo entre a teorização do PNM e as opções epistemológicas propostas pelo chamado "giro decolonial": acreditamos que as lacunas epistemológicas do PNM podem ser adequadamente revistas sob o olhar de intelectuais da América Latina filiados à decolonialidade (Lander, Ed., 2000; Gandarilla, Ed., 2016; Mignolo e Escobar, Eds., 2010; Walsh, Ed., 2005). Além disso, recentemente a teorização decolonial recebeu importantes contribuições a respeito da visualidade (Barriendos, 2008 e 2011; León, 2012), as quais julgamos que em um cotejamento com aportes da geografia cultural o que faremos - lançam interessantes oportunidades de interpretação das paisagens das favelas da América Latina nas quais se instalaram teleféricos. Desse modo, pretendemos demonstrar que muito mais que opções técnicas neutras em atendimento ao transporte urbano, os teleféricos inauguram um regime visual que projeta ideias de modernidade e desenvolvimento e anuncia mudança social, mas que na verdade reforçam a conversão da pobreza em mero valor estético e simbólico. 


\section{As "novas" mobilidades e as opções decoloniais}

Produzidos na maioria das vezes por intelectuais da Europa e anglofônicos, os escritos filiados ao PNM reconhecem a mobilidade como marca distintiva da contemporaneidade. Partem da premissa de que a vida social pressupõe e envolve com cada vez mais frequência movimentos reais ou virtuais de pessoas de lugar a lugar e de evento a evento. Essa "compulsão por movimento" - crescentemente compreendida, também, como direito cidadão e traço distintivo de cosmopolitismo - está direta ou indiretamente ligada a sistemas simultaneamente econômicos, físicos, tecnológicos, políticos e culturais, fazendo com que arranjos afetivos e familiares, relações entre os espaços doméstico e público e concepções de proximidade e distância sejam constantemente reconfigurados. Trata-se, claramente, de um vasto campo de investigação: movimento de corpos e objetos, fluxo de ideias, informações, imagens e capitais, infraestruturas de transportes e comunicação, êxodos e migrações, turismo e viagem (Büscher e Urry, 2009; Sheller e Urry, 2006; Urry, 1995, 2002 e 2007; ver também: Freire-Medeiros, 2016).

Inegavelmente o PNM avança na compreensão do espaço não mais como uma área contínua e estática, de experiência localizada. Adiciona-lhe movimento, potencializando aportes teóricos, inclusive da geografia, que o percebem como uma justaposição de redes e malhas técnicas, sociais e institucionais. Auxilia igualmente na refutação do argumento equivocado sobre o fim da distância e dos territórios - o que o geógrafo brasileiro Rogério Haesbaert (2006) chama de "mito da desterritorialização" ${ }^{3}$. Nesse sentido, nos parece possível estabelecer uma ponte entre o PNM e intelectuais da América Latina que há muito argumentam que o espaço, na contemporaneidade, combina fluxos e fixos, sistemas de objetos e sistemas de ações; que as sociabilidades, interfaces e vivências dos mais diversos grupos sociais com o espaço e no espaço ocorrem tanto com base em lugares específicos quanto com base em novas tecnologias globais de informação e comunicação; e que a

\footnotetext{
${ }^{3}$ Haesbaert submete a um crivo crítico as teorias que a partir de finais do século XX defenderam um conceito de desterritorialização guiado por ideias mistificadoras sobre o fim do estado-nação, das fronteiras, da distância e até mesmo da espacialidade. Para o autor, trata-se de discursos oriundos dos pontos nodais do capitalismo global e que, por isso mesmo, supervalorizam o ciberespaço e naturalizam um mundo sem fronteiras para um capital sem pátria. O autor defende veementemente que não há o fim dos territórios como, aliás, não houve o tão anunciado fim da história - mas a emergência da multiterritorialidade, ou seja, de múltiplos territórios, territorialidades e experiências territoriais, que não se dão de forma uniforme entre lugares e grupos sociais. A marca da contemporaneidade, por isso, ainda é a iniquidade.
} 
dicotomia entre territórios ou redes é falaciosa - há, na verdade, os territórios-redes (de Landa, 1998; de Souza, 1995; Haesbaert, 2006 e 2014; Escobar, 1999 e [2008] 2010; Name, 2012; Santos, [1996] 2002).

No entanto, se autoras e autores vinculados ao PNM percebem o espaço em movimento e em sua dimensão multiescalar, nem sempre se desvencilham de entendimentos tácitos de equilíbrio e continuidade inerentes às mobilidades em análise, que, por sua vez, são apontadas como necessariamente fenômenos do presente. Outro problema é de ordem etnocêntrica: em grande medida, suas formulações teóricas, que dependem de experiências territoriais próprias dos centros urbanos europeus, vêm sendo mal traduzidas para quaisquer experiências de quaisquer grupos em quaisquer territórios. É preciso, portanto, atenção redobrada aos diversos contextos político-culturais e socioeconômicos e às assimetrias de poder que fazem com que mobilidades imperiosamente pressuponham imobilidades que as constituem, definem e possibilitam, notadamente no Sul Global - e, para nós, em particular, nas cidades latino-americanas. A busca excessiva por tudo que se possa adjetivar como "novo" não vem acompanhada de questionamentos em relação a noções eurocêntricas de modernidade e cosmopolitismo (Szerszynki e Urry, 2002 e 2006), animando desconsiderações de elementos de longue durée por trás das mobilidades ditas "contemporâneas": afinal, "a mobilidade não foi inventada pelo telefone móvel" (Cresswell, 2012, p. 646).

É vasta a literatura que aponta que o eurocentrismo, dentro e fora das ciências, sempre ajudou a descrever - ou melhor, legitimar - ações, necessidades e vontades de determinados grupos como se fossem ações, necessidades e vontades universais (Blaut, 1997; Dussel, [1977] 2011; Name, 2013, p. 25-55; Said, [1978] 2007; Shohat e Stam, [1994] 2006; Wallerstein, 1997). A pesquisa sobre as mobilidades contemporâneas, parece-nos, deve dedicar atenção ao quanto pode eventualmente aderir à narração sobre um mundo que já está indiscutivelmente sem fronteiras e com fluxos transnacionais, por isso exigente de que os lugares escolham entre inexoravelmente adaptar-se às redes globais ou perecer (Escobar, 1999, p. 29).

O chamado giro decolonial oferece bases sólidas para desativar muitas destas armadilhas. Ao fornecer molduras teórico-analíticas que desmontam as subjetividades do ser e do 
conhecimento construídos durante o domínio colonial - cujos efeitos ainda são presentes -, constrói uma perspectiva epistemológica própria do Sul Global, em particular do subcontinente latino-americano. Por isso, uma vasta literatura latino-americana (Anzaldúa, [1987] 2012; Escobar, [1995] 2007 e 2005; Mignolo, 2000 e [1995] 2010; Moraña et al., 2008; Gandarilla, [2014] 2015; Restrepo e Rojas, 2010; Vallega, 2014) vem buscando pôr em evidência tal colonização epistêmica que contrapõe a modernidade/racionalidade europeia a outras formas de conhecimentos e experiências. A intenção é não apenas questionar essas hierarquias epistêmicas, mas igualmente propor a concepção e criação efetiva de outros mundos possíveis.

Intelectuais decoloniais têm se dedicado a demonstrar que o eurocentrismo põe em movimento um pensamento único sobre o mundo formulado e reforçado durante o processo de colonização europeia na América, que se reproduziu - e ainda se reproduz, no globalismo do presente - por meio da "colonialidade do poder" (Quijano, 1992, 2000a, 2000b, [2001] 2005; Quijano e Wallerstein, 1992). Essa noção central refere-se a práticas e discursos opressores e violentos - nos planos material e simbólico -, inerentes à formulação da ideia da Europa como uma identidade que secularmente vem emergindo de processos de distinção em relação a outras culturas. Assim, a invenção da branquitude como a visibilidade da identidade ética capitalista (Echeverría, 2010, p. 57-86) tem enorme centralidade: indissociável da invasão da América e da exploração colonial, forja uma classificação social que mescla hierarquicamente os territórios à ideia de "raça" - geo-historicamente reproduzida e codificada como diferença étnica, antropológica, cultural, intelectual, nacional, geográfica, climática, paisagística ou de gênero, por exemplo (Lugones, 2008 e 2011; Mignolo, [2005] 2007 e 2011; Segato, 2015). ${ }^{4}$

O giro decolonial tende a valorizar, portanto, o que às vezes parece se perder na produção filiada ao PNM: a certeza de que nem tudo que é apresentado como novo o é tanto assim, podendo haver genealogias de longa duração e estruturalmente conflitivas. Com clareza revelam que a globalização, a despeito da perda de hegemonia do Estado-Nação, não

\footnotetext{
${ }^{4}$ Não se deve confundir, contudo, a colonialidade com o colonialismo: a racionalidade moderno-colonial apresentou-se e ainda se apresenta na constante relação hierárquica entre países que deliberadamente confundem "raça" e origem espacial (como os "latinos" nos Estados Unidos) e na concentração da pobreza, dos trabalhos subalternos e das vulnerabilidades socioambientais junto à população mundial de "cor", por exemplo.
} 
rompe de fato com o projeto moderno-colonial, etnocêntrico e hierárquico, que segue atuando sobre a relação entre os lugares e grupos sociais; e que ideias e imagens de civilização, progresso e desenvolvimento continuam sendo parte de um discurso de manutenção da diferença colonial, escamoteando conteúdos elaborados e naturalizados pela colonialidade.

\section{Paisagens, tecnologias da visão e colonialidade do ver: os teleféricos nas favelas latino-americanas}

Críticas de intelectuais da América Latina aos projetos urbanos com base no planejamento estratégico costumam apontar que eles empregam grandes quantidades de recursos dos cofres públicos, ignoram ou flexibilizam normas legais e causam aumento dos valores do solo. Além disso, quase sempre não têm origem em reais necessidades locais nem contam com participação social ao longo de seu projeto e sua implantação (Carmona e Arrese, 2005; Cuenya, 2009 e 2011; Cuenya et al., Eds., 2013; Vainer et al., 2012; Lungo, Ed., 2004; Mascarenhas, 2016; Sánchez, 2003). Também reclama-se que a despeito de ocorrerem em cidades de perfis e portes distintos, na maioria das vezes são inspirados por experiências europeias - de Barcelona e Berlim, em especial (Arantes, 2012). Se no caso das favelas da Colômbia, Bolívia, Venezuela e Brasil que receberam teleféricos o modelo projetivo tem outra referência geográfica- a latino-americana Medellín -, não deixam de transformar a paisagem e instituir marcos visuais - e, consequentemente, novas imagens urbanas.

As investigações filiadas ao PNM percebem no tempo presente as marcas de certo cosmopolitismo global, no qual a curiosidade geográfica e a mobilidade extensiva são fatores fundamentais. Uma cultura cosmopolita teria relação com mulheres e homens cada vez mais abertos a conhecer novas pessoas, lugares e culturas (Bauman, 1993; Beck, 2000; Urry, 1995). Na impossibilidade de - ou em complemento aos - deslocamentos físicos, lançariam mão de elementos (áudio)visuais como forma de interação com outros espaços e pessoas. Assim, as "viagens imaginativas" (Urry, 2000, 2007 e 2008; Szerszynski e Urry, 2002 e 2006; Larsen e Urry, 2011a e 2011b) possibilitariam seu acesso constante a lugares 
fisicamente distantes por meio do consumo de imagens produzidas pelas mídias, com destaque para a internet, que reconfigura e intensifica novos tipos e formas de mobilidade. Não se trata, porém, de um fenômeno novo: a discussão faz lembrar antigas observações do geógrafo John K. Wright (1947) a respeito de "geografias imaginativas", ou "informais", segundo ele presentes em trabalhos não científicos - livros de viagem, revistas e jornais, livros de ficção e poesias, telas de pintura e do cinema - fazendo com que nenhum lugar seja completamente desconhecido e gerando curiosidade sobre todos os lugares. Bem antes disso, mapas, pinturas e desenhos de viajantes e exploradores coloniais cumpriam esta função, rivalizando com as representações espaciotemporais nativas e preenchendo o que convenientemente se julgava território vazio com a imaginação geográfica europeia (Cosgrove, 2001 e 2008; Dym e Offen, Eds., 2011; Mignolo, [1995] 2010, p. 219-313).

Nesse sentido, apontamos mais três problemas na análise das imagens e viagens imaginativas defendidas nos escritos do PNM. O primeiro: há certo grau de eurocentrismo nas concepções de cosmopolitismo que, nesta literatura, estão baseadas na falsa ideia de acesso universal e equânime à internet e outras mídias, sendo por isso dificilmente aplicáveis aos contextos de desigualdade, violência e pobreza urbana a que muitos grupos estão submetidos nas cidades latino-americanas. O segundo: são aportes que não têm dado muita importância ao fato de que a grande maioria destas imagens em circulação a respeito de lugares distantes são imagens de paisagens, das quais faz-se usos objetivos e subjetivos. O terceiro: é recorrente o entendimento dessas imagens restritivamente em contextos e circuitos do turismo, em detrimento de outras situações em que também estão presentes.

A paisagem, como se sabe, é um conceito-chave da geografia (Claval, 2004; Holzer, 1999; Name, 2010), vigorosamente visual, que é tanto traço da natureza quanto objeto da cultura (Berque, 1994). É também o resultado de intencionalidades geo-historicamente produzidas e reproduzidas com vistas a se relacionar uma imagem visual a um mundo material, em que se envolvem questões sensoriais e estéticas. Para que o espaço observado se converta em paisagem há que se investir, a um só tempo, em tecnologias de representação e de espetacularização. É nessa direção que Denis Cosgrove aponta que as ideias e as experiências moderno-coloniais relacionadas à paisagem evoluíram em íntima relação com o que chama de "tecnologias de visão": no contexto histórico de invenções renascentistas 
concomitantes à ampliação de deslocamentos e viagens da colonização, a visualização e representação de paisagens se beneficiaram das técnicas da cartografia e da perspectiva, da invenção de microscópios e telescópios e da formação de um novo olhar sobre a natureza (Cosgrove, 2003; ver também: Ronai, 1976 e 1978). Mais tarde, tiveram seu poder de persuasão ampliado, quer por conta de um turismo cada vez mais massivo, quer pelo crescente fluxo de imagens de paisagens nas diversas mídias inseridas no cotidiano (fotografia, cinema, televisão, computação gráfica).

Na medida em que técnicas ou tecnologias jamais são neutras, vale a pena trazer à discussão os argumentos de Joaquín Barriendos (2008 e 2011) a respeito da "colonialidade do ver". Referindo-se à cartografia e aos registros visuais etnográficos coloniais, o historiador mexicano aponta que havia uma predileção por imagens reducionistas, estereotipadas e degradantes das populações nativas, seus hábitos, sua cultura e seus espaços. Esses registros, que geo-historicamente influenciaram a produção de imagens, eram e ainda são representações que classificam o Outro de acordo com códigos que relacionam e hierarquizam corpos, natureza e cultura pelo que delas se pode apreender visualmente. De lá para cá, ampliaram-se os meios de reprodução, arquivamento e transmissão (Benjamin, [1936] 1994; Kittler, [1999] 2016), mas as imagens desde muito circularam. Permanecem, ainda, a hierarquização de lugares e grupos sociais: oposições binárias entre civilização e barbárie, cidade e campo ou urbe e favela, por exemplo, geohistoricamente muito se apoiaram em paisagens e imagens que as definiam.

A favela latino-americana está envolta em diferentes circuitos e interconexões entre paisagens e imagens. Uma análise geo-histórica e comparativa revela um repertório imagético, eurocêntrico, consagrador da favela latino-americana como "paisagem-tipo" (Sauer, [1925] 2007; Troll [1950] 2007): muito embora as favelas assumam várias morfologias, a mais constantemente apresentada em imagens é aquela cuja paisagem é de construções rudimentares, encostas íngremes e pobreza - como as que vêm recebendo teleféricos -, associada ao que geo-historicamente foi instituído como paisagem "tropical" ou "andina", por exemplo. Soma-se a presença de corpos não brancos e, assim, paisagem e "raça" tornam-se os dois lados de uma mesma moeda: dados visuais capazes de servir a postulados imagéticos sobre dissonância, inferioridade ou exotismo (Name, 2013, p. 39). Ao 
longo do tempo, as imagens desta paisagem-tipo da favela estiveram em meio a práticas de exibição e ocultamento: ora de seus atributos "singulares", "vernáculos" ou "autênticos", ora de tudo que nelas representa o indesejável, vexatório e recriminável por ser próprio do subdesenvolvimento e do atraso, mas que por isso mesmo necessariamente está à espera de melhorias urbanas e sociais (Cardoso, 2006; Duno Gottberg, 2010; Freire-Medeiros, 2009, 2016; Freire-Medeiros e Menezes, 2009 e 2016; Name, 2013 e 2017; Novaes, 2014; Rodrigues, 2014 e 2017; Vitale, 2013;).

No entanto, a mais importante característica desta colonialidade do ver é o fato de que ao mesmo tempo em que estas imagens inferiorizam o Outro, também desterritorializam o self daquele que lança o olhar. Oculta-se o ponto de vista - e, portanto, de enunciação - que as produziu, e, por isso, a autoria das imagens - de corpos a paisagens - apresenta-se como se desprovida de qualquer dado de etnicidade, gênero e classe. Assim, cabe lembrar do que na década de 1970 alguns escritos da geografia francesa sobre paisagens já argumentavam: se uma análise de paisagens parte da objetividade do ponto de vista de onde se observa o espaço - a localização -, de modo a se problematizar seus efeitos estéticos, psicológicos e emocionais, também deve levar em conta o ponto de vista - nesse caso, os interesses e as ideologias - dos grupos sociais que as produziram, ou que elegeram o ângulo de sua observação. É neste jogo entre materialidades e mentalidades que a paisagem, enfim, ganha a capacidade de mascarar ou expor todo tipo de conflitos (Cohen, 1987; Collot, 1986; Giblin, 1978; Lacoste 1977; Sautter, 1979).

Christian León (2012) afirma que a colonialidade do ver se renova, na atualidade, a partir do que nomeia como "telecolonialidade", ou seja, do papel que cumprem os meios audiovisuais na administração de imagens à distância para o controle geopolítico da alteridade em nível global. Mediante o contexto da contemporânea feição cognitiva do capitalismo, marcada pelas tecnologias de comunicação e de imagens, pela cultura visual, pela indústria cultural e pela espetacularização social e urbana, o sociólogo equatoriano insiste que os dispositivos audiovisuais ainda vêm realizando uma incorporação modernocolonial do Outro nos termos dicotômicos da alteridade. Ao mesmo tempo, a reprodutibilidade crescente das fotografias, a manipulação do tempo e do movimento pelos filmes, as transmissões simultâneas e ao vivo da televisão e a instantaneidade e 
simultaneidade das imagens digitais compartilhadas na internet sustentam um complexo processo de sincronização de distintas temporalidades, o que contribui para a maior difusão destas representações e sua aderência no senso comum. Ainda que se possa ver um sentido de cosmopolitismo na difusão e no compartilhamento global destas imagens, não se deve ignorar que elas têm sido geo-historicamente produzidas e consumidas em processos atravessados pelos pontos de vista de grupos dominantes que visam a tornar pessoas, grupos sociais e lugares - não somente, mas em especial, do Sul Global - subalternos e invisíveis.

Barriendos e León permitem-nos reinterpretar, a partir da decolonialidade, os argumentos sobre o ocularcentrismo moderno-colonial intimamente ligado à criação e à reprodução de paisagens, o cosmopolitismo global e as viagens e geografias imaginativas. No contexto de saturação de imagens em circulação e no qual se ampliam os modos de mercantilização do espaço urbano, as paisagens são também mercadorias. No caso dos teleféricos em favelas latino-americanas, o relevo acidentado, a morfologia complexa de suas edificações e a população "racializada" destas áreas pauperizadas são elementos de estranheza e alteridade convertidos a valor agregado. Com a obtenção de diferentes pontos de vistas de paisagens panorâmicas, a pobreza é a própria diferença colonial (Mignolo, 2011) que contraditoriamente é o valor que toma a favela como o Outro da cidade.

No entanto, a inclusão de teleféricos inaugura um regime imagético e paisagístico que anuncia promessas de progresso e desenvolvimento, num futuro qualquer.

\section{Apontamentos finais}

Sugere-nos o antropólogo colombiano Arturo Escobar que "políticas públicas, ... assim como grande parte do que se denomina projeto, são tecnologias políticas fundamentais da modernidade e elementos-chave na constituição moderna de um só mundo globalizado" (Escobar, 2016, p. 15). Assim, com base em preceitos do PNM, uma análise desatenta das intervenções sob a égide do planejamento urbano estratégico, as quais se incluem os teleféricos em favelas latino-americanas, poderia interpretá-las como um sinal de 
cosmopolitismo: estaríamos diante de mobilidades de projetos, paisagens e imagens alimentadoras de um sentido coeso e global em torno de ideias e experiências supostamente universais de urbanidade.

Não nos parece ser este o caso. Julgamos ter demonstrado que os fios, cabos e cabines dos teleféricos instalados em áreas íngremes e pauperizadas de cidades da América Latina atraem novos olhares e proporcionam novos pontos de vista produtores de novas paisagens e imagens da favela. No entanto, em sendo não só dispositivos de mobilidade mas também tecnologias da visão, eles as convertem em espetáculos que devem ser vistos de cima, de longe e de uma só vez: de dentro da cabine, o olhar está sob uma nova perspectiva, com profundidade e do alto, a perder de vista; o olhar de quem está mais longe, fora da cabine, vê estas favelas enquadradas num horizonte de montanhas densamente ocupadas, mas redesenhado pelas cabines suspensas e em movimento (Freire-Medeiros e Name, 2015).

Assim, estes projetos urbanos e suas imagens também projetam: a ideia de uma favela que, ainda que muito marcada pela pobreza, está às portas da modernidade - por sua vez obtida justamente pela instalação do dispositivo de mobilidade; um enquadramento dos espaços de moradia pauperizados como uma paisagem agora não mais tão vergonhosa e, por isso, passível de ser reproduzida tecnicamente na forma de imagem; e, por fim, uma nova biografia de cidades - e das próprias favelas -, antes reconhecidas pela pobreza e pela violência, mas que agora são anunciadas como territórios competitivos no mercado global de investimentos, o que é bastante desejável pelo poder público e segmentos do setor privado.

Igualmente são parte de um modelo de cidade acrítico em relação à permanência de estruturas de domínio moderno-colonial: análises recentes a respeito do transporte por cabos em Medellín e no Rio de Janeiro (Álvarez e Bocarejo, 2014; Bocarejo e Álvarez, 2012; Brand e Dávila, 2012; Dávila, Ed. 2012; Dávila e Brand, 2012; Dávila e Daste, 2011; FreireMedeiros e Name, 2015 e 2017; Leibler e Musset 2010) apontam que as decisões a respeito de sua implantação não foram conduzidas por processos verdadeiramente participativos junto às comunidades e que tem pouco impacto sobre a (i)mobilidade da maioria dos seus residentes. Especificamente sobre o caso colombiano, Álvarez e Bocarejo (2014) argumentam que "para os políticos e urbanistas, os teleféricos oferecem novas formas de 
governar a pobreza urbana, ao mesmo tempo em que trazem a promessa de valorização de suas cidades do Terceiro Mundo".

Acreditamos que o mesmo argumento é válido no caso dos teleféricos de outras cidades latino-americanas. Seu valor é excessivo se comparado ao impacto na mobilidade dos desfavorecidos, mas mesmo transportando apenas alguns residentes para apenas algumas estações escassamente localizadas em favelas densamente povoadas, são promovidos como uma clara indicação de desenvolvimento e progresso futuros. A repaginação estética da paisagem e as imagens que possibilitam ganhos políticos e criam um clima favorável a negócios urbanos são o que ao planejamento urbano estratégico parece mais importar.

\section{Referências bibliográficas}

ÁLVAREZ, M.J.R. e BOCAREJO, D. Beautifying the slum: cable car fetishism in Cazucá, Colombia. International Journal of Urban and Regional Research, v. 38, n. 6, p. 2025-2041, 2014.

ANZALDÚA, G. Bordelands/La frontera. San Francisco: Aunt Lute Books, (1987) 2012.

AMANCIO, T. O Brasil dos gringos. Niterói: Intertexto, 2000.

ARANTES, O.B.F. Berlim e Barcelona: duas imagens estratégicas. São Paulo: Annablume, 2012

ASCHER, F. Les nouveaux principes de l'urbanisme. Éditions de l'Aube, 2001.

BENJAMIN, W. A obra de arte na era de sua reprodutibilidade técnica. In: Magia, técnica, arte e política (Obras escolhidas). São Paulo: Brasiliense, (1936) 1994, p. 165-196.

BERQUe, A. Paysage, milieu, histoire. In: BERQUE, A. (Ed.). Cinq propositions pour une théorie du paysage. Seyssel: Champ Vallon, 1994, p. 11-29.

BARRIENDOS, J. Apetitos extremos. La colonialidad del ver y las imágenes-archivo sobre el canibalismo de Indias. Transversal, p. 1-20, 2008.

BARRIENDOS, J. La colonialidad del ver. Hacia un nuevo diálogo visual interepistémico. Nómadas, n. 35, p. 1330, 2011.

BAUMAN, Z. Postmodern ethics. Oxford: Blackwell, 1993.

BECK, U. The cosmopolitan perspective: sociology of the second age of modernity. The British Journal of Sociology, v. 1, n. 1, p. 79-105, 2000.

BLAUT, J.M. The colonizer's model of the world. New York/London: The Guilford Press, 1993.

BOCAREJO, D. and ALVAREZ, M.J.R. La esperanza de ser vistos. Percepciones de los habitantes de la Comuna 4 frente a la posible construcción de un cable aéreo. In: DÁVILA, J.D. (Ed.). Movilidad urbana y pobreza: aprendizajes de Medellín y Soacha, Colombia. Bogotá: The Development Planning Unit, 2012, p. 143-148.

BORSDORF, A. Hacia la ciudad fragmentada. Tempranas estructuras segregadas en la ciudad latinoamericana". Scripta Nova, v. 146, n. 122. 2003 
BORJA, J. y CASTELLS, M. Local y global: la gestión de las ciudades en la era de la información. Madrid: Taurus, 1998.

BRAND, P. e DÁVILA, J.D. Los metrocables y el "urbanismo social": dos estrategias complementarias. In: DÁVILA, J.D. (Ed.). Movilidad urbana y pobreza: aprendizajes de Medellín y Soacha, Colombia. Bogotá: The Development Planning Unit, 2012, p. 38-46.

BÜSCHER, M. e URRY, J. Mobile methods and the empirical. European Journal of Social Theory, v. 12, n. 1, p. 99-116, 2009.

CARDOSO, C. Do espaço concebido ao espaço vivido: um estudo de caso sobre as representações espaciais $e$ identidades da Favela da Maré, RJ. Tese - Doutorado em Geografia. Universidade Federal Fluminense. Niterói, 2006.

CARMONA, M. e ARRESE, A. Globalización y grandes proyectos urbanos: la respuesta de 25 ciudades. Buenos Aires: Infinito, 2005.

CLAVAL, P. A paisagem dos geógrafos. In: CORRÊA, R.L. e ROSENDAHL, Z. (Eds.). Paisagens, textos e identidade. Rio de Janeiro: EdUERJ, p. 13-74, 2004.

COHEN, E. e COHEN, S.A. Beyond Eurocentrism in tourism: a paradigm shift to mobilities. Tourism Recreation Research, v. 40, n. 2, p. 1-12, 2015 a.

COHEN, E. e COHEN, S.A. A mobilities approach to tourism from emerging regions. Current Issues in Tourism, v. 18 , n.1, p. 11-43, 2015b.

COHEN, S. e GÖSSLING, S. A darker side of hypermobility. Environment and Planning A, n. 47, p. 1661-1679, 2015.

COHEN, S. Points de vue sur les paysages. Hérodote, n. 44, p. 38-44, 1987.

COLLOT, M. Points de vue sur la perception des paysages. L'espace géographique, v. 15, n. 3, p. 211-217, 1986.

COSGROVE, D. Apollo's eye. Baltimore: The John Hopkins University Press, 2001.

COSGROVE, D. Landscape and the European sense of sight-eyeing nature. In: ANDERSON, K., DOMOSH, M., PILE, S. e THRIFT, N. (Eds.). Handbook of Cultural Geography. London: Sage, 2003, p. 249-268.

COSGROVE, D. Geography and vision: seeing, imagining and representing the world. London/New York: I.B. Tauris, 2008.

CRESSWELL, T. Mobilities II: still. Progress in Human Geography, v. 36, n. 5, p. 645-653, 2012.

CUENYA, B. Grandes proyectos urbanos latinoamericanos: aportes para su conceptualización y gestión desde la perspectiva del gobierno local. Cuaderno urbano, v. 8, n. 8, p. 229-252, 2009.

CUENYA, B. Grandes proyectos y sus impactos en la centralidad urbana. Cadernos Metrópole, v. 13, n. 25, 2011.

CUENYA, B., NOVAIS, P. e VAINER (Eds.). Grandes projetos urbanos. Porto Alegre: Masquatro Editora, 2013.

DÁVILA, J.D. (Ed.). Movilidad urbana y pobreza: aprendizajes de Medellín y Soacha, Colombia. Bogotá: The Development Planning Unit, 2012.

DÁVILA, J.D. e BRAND, P. La gobernanza del transporte público urbano: indagaciones alrededor de los Metrocables de Medellín Revista Bitácora Urbano Territorial, v. 21, n. 2, p. 85-96, 2012.

DÁVILA, J.D. e DASTE, D. Pobreza, participación y metrocable. Estudio del caso de Medellín. Boletín CF+S, n. 54, p. 121-131, 2011.

DE LANDA, M. Meshworks, hierarchies and interfaces. In: BECKMANN, J. (Ed.). The virtual dimension. New York: Princeton Architectural Press, 1998, p. 274-285.

DE SOUZA, M.L. O território: sobre espaço e poder, autonomia e desenvolvimento. In: DE CASTRO, I.E., GOMES, P.C.C., CORRÊA, R.L. (Eds.). Geografia: conceitos e temas. Rio de Janeiro: Bertrand, 1995, p. 77-116.

DE SOUZA, M.L. Mudar a cidade. Rio de Janeiro: Bertrand, 2001. 
DYM, J. e OFFEN, Karl. (Eds.) Mapping Latin America: a cartographic reader. University of Chicago Press, 2011.

DUNO GOTTBERG, L. Geografías del miedo en el cine venezolano: Soy un delicuente (1976) y Secuestro express (2005). Ensayos, no 19, p. 40-64, 2010.

DUSSEL, E. Filosofía de la liberación. México: FCE, (1977) 2011.

ECHEVERRÍA, B. Modernidad y blanquitud. México: Editorial Era, 2010.

ELLIOT, A e. URRY, J. Mobile lives. London: Routledge, 2010.

ESCOBAR, A. El final del salvaje. Bogotá: ICAN/CEREC. 1999.

ESCOBAR, A. Más allá del Tercer Mundo. Bogotá: ICAN/CEREC, 2005.

ESCOBAR, A. La invención del Tercer Mundo. Caracas: Fundación Editorial El perro y la rana, (1995) 2007.

ESCOBAR, A. Territorios de diferencia: lugar, movimientos, vida, redes. Popayán: Envión Editores, (2008) 2010.

ESCOBAR, A. Autonomía y diseño. Popayán: Universidad del Cauca/Sello Editorial, 2016.

FREDIANI, J.C. Las nuevas periferias en el proceso de expansión urbana. El caso del partido de La Plata. Geograficando, v. 5, n. 5, p. 103-125, 2009.

FREIRE-MEDEIROS, B. The favela and its touristic transits. Geoforum, v. 40, p. 580-588, 2009.

FREIRE-MEDEIROS, B. Touring Poverty. London: Routledge, 2013.

FREIRE-MEDEIROS, B. In Memoriam: John Urry (1946-2016). Plural, v. 23, p. 138, 2016.

FREIRE-MEDEIROS, B. e MENEZES, P. Fotografando a pobreza turística. Revista Anthropológicas, v. 20, p. 11-11, 2009.

FREIRE-MEDEIROS, B. e MENEZES, P. As viagens da favela e a vida social dos suvenires. Sociedade e Estado, v. 31, p. 651-670, 2016.

FREIRE-MEDEIROS, B. e NAME, L. Flying for the very first time: mobilities, social class and environmental concerns in a Rio de Janeiro favela. Mobilities, v.8, n. 2, p. 167-184, 2013.

FREIRE-MEDEIROS, B. e NAME, L. 'Peace, love \& fun': an aerial cable car and the traveling favela. In: CIDELL, J. e PRYTHERCH, D. Transport, mobility, and the production of urban space. New York/London: Routledge, 2015, p. 263-280.

FREIRE-MEDEIROS, B. e NAME, L. Does the future of the favela fit in an aerial cable car? Examining tourism mobilities and urban inequalities through decolonial lens. Canadian Journal of Latin American and Caribbean Studies, v. 42, n. 1, p. 1-16, 2017.

FUKUYAMA, F. e COLBY, S. Half a Miracle. Foreign Policy, v. 25, 2011.

GANDARILLA, J.G.S. Modernidad, crisis y crítica. México: UNAM, (2014) 2015.

GANDARILLA, J.G.S. (Ed.). La crítica en el margen. México D.F.: Akal/Inter Pares, 2016.

GIBLIN, B. Le paysage, le terrain et les géographes. Hérodote, n. 9, p. 74-89, 1978.

GITLIN, T. Media unlimited. New York: Metropolitan Books, 2001.

GROSFOGUEL, R. La descolonización de la economía política y los estudios postcoloniales: transmodernidad, pensamiento fronterizo y colonialidad global. Tabula Rasa, n. 4, p. 17-48, 2006.

HAESBAERT, R. O mito da desterritorialização. Rio de Janeiro: Bertrand, 2006.

HAESBAERT, R. Viver no limite. Rio de Janeiro: Bertrand, 2014.

HARVEY, D. From managerialism to entrepreneurialism: the transformation in urban governance in late capitalism. Geografiska Annaler, v. 71B, n. 1, p. 3-17, 1989.

HOLZER, W. Paisagem, imaginário, identidade: alternativas para o estudo geográfico. In: CORRÊA, R.L. e ROSENDHAL, Z. (Eds.). Manifestações da cultura no espaço. Rio de Janeiro: EdUERJ, 1999, p. 149-168. 
KEELING, D.J. Transportation geography: new directions on well-worn trails. Progress in Human Geography, v. 31, n. 2, p. 217-225, 2007.

KEELING, D.J. "Transportation geography: local challenges, global contexts". Progress in Human Geography, v. 33, n. 4, p. 516-526, 2009.

KITTLER, F. Mídias ópticas. São Paulo: Contraponto, (1999) 2016.

LACOSTE, Y., A quoi sert le paysage? Qu'est-ce un beau paysage? Hérodote, v. 7, p. 3-41. 1977

LANDER, E. (Ed.). La colonialidad del saber. Buenos Aires: CLACSO, 2000.

LARSEN, J. e URRY, J. The tourist gaze 3.0. Thousand Oaks: Sage Publications, 2011a.

LARSEN, J. e URRY, J. Gazing and performing. Environment and Planning D: Society and Space, v. 29, n. 6, p. 1110-1125, 2011b.

LEIBLER, L. e MUSSET, A. ¿Un transporte hacia la justicia espacial? El caso del Metrocable y de la Comuna Nororiental de Medellín, Colombia. Scripta Nova, v. 331, n. 48, 2010.

LEÓN, C. Imagen, medios y telecolonialidad: hacia uma crítica decolonial de los estudios visuales. Aisthesis, v. 51 , p. 109-123.

LIMONAD, E. Urbanização dispersa: mais uma forma de expressão urbana?. Revista Formação, vol. 14, n. 1, p. 31-48, 2007.

LUGONES, M. Colonialidad y género. Tabula rasa, n. 9, p. 73-102, 2008.

LUGONES, M. Hacia un feminismo descolonial. La manzana de la discordia, v. 6, n. 2, p. 105-117, 2011.

LUNGO, M. (Ed.). Grandes proyectos urbanos. San Salvador: UCA LILP, 2004.

MASCARENHAS, G. A produção da cidade olímpica e os sinais da crise de um modelo globalitário. GEOUSP: Espaço e Tempo, v. 20, n. 1, p. 52-68, 2016.

MIGNOLO, W.D. Local histories/Global designs. Princenton: Princenton of University Press, 2000.

MIGNOLO, W.D. The darker side of Renaissance. Michigan: The University of Michigan Press, (1995) 2010.

MIGNOLO, W.D. La idea de América Latina. Barcelona: Geodisa Editorial, (2005) 2007.

MIGNOLO, W.D. The darker side of Western Modernity. Durham/Londres: Duke University Press, 2011.

MIGNOLO, W.D. e ESCOBAR, A. (Eds.). Globalization and the decolonial option. Londres: Routledge, 2010.

MORAÑA, M., DUSSEL, E. e JÁUREGUI, C.A. (Eds.). Coloniality at large. Durhan/London, Duke University Press, 2008.

NAME, L. O conceito de paisagem na geografia e sua relação com o conceito de cultura. GeoTextos, v. 6, n. 1, p. 163-186, 2010.

NAME, L. Das redes às ruas: novas tecnologias de informação e comunicação, mobilização social e manifestações políticas no espaço público In: RHEINGANTZ, P.A. e PEDRO, R. (Eds.). Qualidade do lugar e cultura contemporânea. Rio de Janeiro: FAU/PROARQ, 2012, p. 199-214.

NAME, L. Geografia pop: o cinema e o Outro. Rio de Janeiro: Apicuri/Editora PUC-Rio, 2013.

NAME, L. Caracas e Mérida, Venezuela: colonialidade territorial e gênero no filme "Azul y no tan rosa". Revista Latino-Americana de Geografia e Gênero, 2017 (no prelo).

NOVAES, A.R. Favelas and the divided city: mapping silences and calculations in Rio de Janeiro's journalistic cartography. Social \& Cultural Geography, v. 15, n. 2, p. 201-225, 2014.

NOVAIS, P. Uma estratégia chamada "planejamento estratégico". Rio de Janeiro: 7Letras, 2010.

ORTIZ, R.V.O. e URDANETA, J. Políticas públicas de transporte urbano en Venezuela. Mundo Nuevo: Revista de Estudios Latinoamericanos, v. 4, n. 9, p. 217-244, 2012. 
PAQUETTE, C. Retos del desarrollo urbano. In: INSTITUT DES AMÉRIQUES (Ed.). Los Desafíos del Desarrollo en América Latina: Dinámicas Socioeconómicas y Políticas Públicas. Paris: AFD, 2014, p. 195-211.

QUIJANO, A. Colonialidad y modernidad/racionalidad. Perú Indígena, n. 13, p. 11-29, 1992.

QUIJANO, A. Colonialidad del poder, eurocentrismo y América Latina. In LANDER, E. (Ed.). La colonialidad del saber. Buenos Aires: CLACSO, 2000a, p. 201-246.

QUIJANO, A. ¡Qué tal raza! Revista venezolana de economía y ciencias sociales, v. 6, n. 1, p. 37-45, $2000 \mathrm{~b}$.

QUIJANO, A. Colonialidade do poder, globalização e democracia. Novos Rumos, v. 17, n. 37, p. 4-28, (2001) 2005.

QUIJANO, A. e WALLERSTEIN, I. Americanity as a concept. Or the Americas in the modern world. International Social Science Journal, v. 44, n. 4, p. 549-557, 1992.

REIS, N.G. Notas sobre urbanização dispersa e novas formas de tecido urbano. São Paulo: Via das Artes, 2006.

RESTREPO, E. e ROJAS, A. Inflexión decolonial: fuentes, conceptos y cuestionamientos. Instituto de Estudios Sociales y Culturales Pensar, 2010.

RODRIGUES, L. Urbanismo do Apocalipse: a favela carioca como um filme de ficção científica. Trabalho de Conclusão de Curso (Graduação em Arquitetura e Urbanismo) - Universidade Federal Fluminense, Niterói, 2014.

RODRIGUES. L. A Unidade de Polícia Pacificadora através dos mapas do jornal "O Globo": uma narrativa da conquista territorial da favela carioca. Dissertação (Mestrado em Geografia) - Universidade do Estado do Rio de Janeiro. Rio de Janeiro, 2017.

ROLNIK, R. E KLINTOWITZ, D. (I)Mobilidade na cidade de São Paulo. Estudos Avançados, v. 25, n. 71, p. 89-108, 2011.

RONAI, M. Paysages. Hérodote, v. 1, p. 125-159, 1976.

RONAI, M. Paysages II. Hérodote, v. 7, p. 71-91, 1977.

SAID, E.W. Orientalismo. São Paulo: Companhia das Letras, (1978) 2007.

SÁNCHEZ, F. A reinvenção das cidades para um mercado mundial. Argos: Editora Universitária, 2003.

SANTOS, M. A natureza do espaço. São Paulo: EdUSP, (1996) 2002.

SAUER, C.O. The morphology of landscape. In: WIENS, J.A., MOSS, M.M., TURNER, M.G. e MLADENOFF, D.J. (Eds.). Foundation papers in landscape ecology. New York: Columbia University Press, (1925) 2007, p. 36-70.

SAUTTER, G. Le paysage comme connivence. Hérodote, n. 16, p. 40-67, 1979.

SEGATO, R.L. La crítica de la colonialidad en ocho ensayos: y una antropología por demanda. Buenos Aires: Prometeo, 2015.

SHELLER, M. e URRY, J. The new mobilities paradigm. Environment and planning A, v. 38, n. 2, p. 207-226, 2006.

SHOHAT, E. e STAM, R. Unthinking eurocentrism: multiculturalism and the Media. London/New Yoir: Routledge, 1994.

SZERSZYNSKI, B. e URRY, J. Cultures of cosmopolitanism. The Sociological Review, v. 50, n. 4: p. 461-481, 2002.

SZERSZYNSKI, B. e URRY, J. Visuality, mobility and the cosmopolitan: inhabiting the world from afar. The British Journal of Sociology, v. 57, n. 1, p. 113-131, 2006.

TROLL, C. The geographic landscape and its investigation. In: WIENS, J.A., MOSS, M.M., TURNER, M.G. e MLADENOFF, D.J. (Eds.). Foundation papers in landscape ecology. New York: Columbia University Press, (1950) 2007, p. 71-101.

URETA, S. To move or not to move? Social Exclusion, accessibility and daily mobility among the low-income population in Santiago, Chile. Mobilities, v. 3, n. 2, p. 269-289, 2008. 
URRY, J. The tourist gaze. London: Sage, 1995.

URRY, J. Mobile sociology. The British Journal of Sociology, v. 51, n. 1, p. 185-203, 2000.

URRY, J. Mobility and proximity. Sociology, v. 36, n. 2, p. 255-274, 2002.

URRY, J. Mobilities. London: Polity Press, 2007.

VAINER, C.B. Pátria, empresa e mercadoria. In: ARANTES, O. VAINER. C e MARICATO. A cidade do pensamento único. Petrópolis: Editora Vozes, 2000, p. 75-103.

VAINER, C.; DE OLIVEIRA, F.L. e NOVAIS, P. Notas metodológicas sobre a análise de grandes projetos urbanos. In: DE OLIVEIRA, F.L., CARDOSO, A.L. COSTA, H.S.M. e VAINER, C.B. (Eds.). Grandes projetos metropolitanos: Rio de Janeiro e Belo Horizonte. Rio de Janeiro: Letra Capital, 2012, p. 11-23.

VALLEGA, A.A. Latin American Philosophy from identity to exteriority. Bloomington/Indianapolis: Indiana University Press, 2014.

VITALE, P. Miradas sobre la villa. Política y fotografía en asentamientos populares de Buenos Aires. Serie urbana, n. 4, p. 37-52, 2013.

WALLERSTEIN, I. Eurocentrism and its avatars: the dilemmas of social science. Sociological Bulletin, v. 46, n. 1: p. 21-29, 1997.

WALSH, C. (Ed.). Pensamiento crítico y matriz colonial. Quito, UASB-Abya Yala, 2005.

WRIGHT, J.K. Terrae incognitae: The place of the imagination in geography. Annals of the Association of American Geographers, v. 37, n. 1, p. 1-15, 1947. 